\title{
Part Three Summary: Communicating into the Future
}

\author{
Deanne K. Bird and Katharine Haynes
}

The chapters that form Part Three explore diverse and wide-ranging communication and engagement processes, where old practices and new technologies are brought together to reduce the impact of volcanic crises in an increasingly globalised world. The chapters highlight challenges of working across disciplines, sectors, institutions, and negotiating differing politics and cultural practices and knowledges. Overall, Part Three demonstrates that trans-disciplinary and multi-organisational partnerships that include social scientists, health professionals, civil defence experts and community members alongside volcanologists, are key to successful volcanic risk reduction. These partnerships must be developed well before a crisis in order that trust, shared meaning and effective working relationships are developed. Part Three also considers progress made and identifies areas that need to be addressed to ensure the success of volcanic crisis communication in the near and long term.

In order to set the scene, Chester et al. in the chapter entitled "Communicating Information on Eruptions and Their Impacts from the Earliest Times Until the Late Twentieth Century" detail a

D. K. Bird ( $ه)$

Faculty of Life and Environmental Sciences, University of Iceland, 101 Reykjavik, Askja, Iceland e-mail: dkb@hi.is

K. Haynes

Department of Geography and Planning, Macquarie University, Sydney 2109, Australia historic overview of the communication and dissemination of volcanic information. Case studies of the Azores, Portugal and Mt Etna, Italy provide contrasting examples of how responses to volcanic crises and their communication have evolved over time.

Pyle in the chapter entitled "What Can We Learn from Records of Past Eruptions to Better Prepare for the Future?" also considers how observations and accounts, before the advent and application of instrumental monitoring, provide unique perspectives of volcanic processes and impacts and how they can aid future decision-making. Through a retrospective analysis of eruptions of the Kameni islands, Santorini, Greece and Soufriere, St Vincent, Pyle looks at the sequence of volcanic processes and the resulting social, economic and political consequences caused by these events. These case studies highlight the valuable detail contained within contextual data on volcanic activity and how that can be applied to enhance our capacity for reducing risk, particularly where there is a lack of instrumental monitoring.

The importance of community participation, particularly the use of local knowledge is well highlighted by Gabrielsen et al. in the chapter entitled "Reflections from an Indigenous Community on Volcanic Event Management, Communications and Resilience". To date, Ngāti Rangi, an indigenous tribe of Aotearoa, New Zealand living on the flanks of Ruapehu, have not always been included in decision-making during volcanic events despite the benefits their local knowledge would bring to the process, 
particularly in relation to communications and warnings. This chapter however, details how the situation is improving through a community-led initiative where the Ngāti Rangi have set up their own monitoring, information collection, and communication systems.

Cadah et al. in the chapter entitled "Fostering Participation of Local Actors in Volcanic Disaster Risk Reduction" discuss, through the lead author's first hand experiences, case studies of community based DRR at Mount Rainier, USA and Bulusan, Philippines. With references to wider case studies and literature, the chapter identifies the key principles and important considerations for fostering community-based participation. However, the chapter concludes by warning against a rigid and standardised procedure for participation as each volcano and at risk community will have their own specific context and needs. Cadah et al. therefore highlight that flexibility and the development of customized approaches is the way forward.

Further highlighting the need to fully appreciate and comprehend the nuances of each particular locale, Wilmhurst in the chapter entitled "There is no Plastic in Our Volcano: A Story About Losing and Finding a Path to Participatory Volcanic Risk Management in Colombia" describes how the best intentions can lead to failure. A stakeholder workshop, bringing together scientists, government officials, emergency service personnel and at-risk communities was conducted in an effort to create dialogue and cooperation and develop a new participatory path for the management of volcanic risk associated with Galeras, Colombia. On the fourth day, however, the workshop took a very different path, one of mistrust and miscommunication. This chapter challenges all stakeholders to critically think about their role in DRR and how their own assumptions, biases, perceptions and beliefs influence their work. This chapter takes the reader on a journey of getting lost and finding the way again highlighting the many important lessons learnt along the way, many of which are centred around trust.

Continuing the theme of trust, Newhall in the chapter entitled "Cultural Differences and the
Importance of Trust Between Volcanologists and Partners in Volcanic Risk Mitigation" looks at context in relation to cultural differences. As with Wilmhurst, Newhall focuses on the local level, where those in positions of responsibility: scientists, civil defence officials, land managers, engineers, politicians and journalists, as well as at-risk populations, differ greatly with respect to culture. Each of these groups has different concerns, goals, language, approaches, ways of learning and resources. In this chapter Newhall argues that a key to bridging these is trust, which can be earned through understanding and acceptance of, and respect for, the inherent differences. Based on personal experience, Newhall provides a snapshot view of three case studies: Mount St. Helens, USA 1980; Pinatubo, the Philippines 1991; and, Usu, Japan 2000, to highlight the issues of trust and its importance for volcanic risk mitigation. Newhall concludes with some valuable recommendations on how to incorporate professionalism and cross-cultural sensitivity alongside personal touches in every interaction between volcanologists and those who use volcanological information.

In "International Coordination in Managing Airborne Ash Hazards: Lessons from the Northern Pacific", Igarashi et al. examine efforts to bridge cultural divides. Considering air-borne volcanic ash often impacts multiple international jurisdictions, efforts in managing this hazard involve coordination of stakeholders from multiple countries. Through the lens of the 2009 eruption of Sarychev-Peak Volcano in the Kurile Islands and the 2013 eruption of Kliuchevskoi Volcano on the Kamchatka Peninsula, Igarashi et al. identify the challenges of international coordination and strategies to overcome these to ensure the provision of coherent and consistent messaging.

Doyle and Paton further showcase the importance of creating a 'shared meaning' between agencies in "Decision-Making: Preventing Miscommunication and Creating Shared Meaning Between Stakeholders" by examining individual and team decision-making and the critical role of relationships and communication between science advisors, emergency managers and decision 
makers. Doyle and Paton stress that in order to ensure all stakeholders have a shared understanding of the situation and, each other's functions and responsibilities during a time of crisis, they must have built strong relationships through prior training and development.

The communication of probabilities and uncertainties continues to be the Achilles heel of otherwise successful volcanic risk discourse. In "Using Statistics to Quantify and Communicate Uncertainty During Volcanic Crises" Sobradelo and Marti explore the statistical meaning of probability estimates and their role in the quantification and communication of uncertainty during volcanic crises.

Blong et al. in the chapter entitled "Insurance and a Volcanic Crisis - A Tale of One (Big) Eruption, Two Insurers, and Innumerable Insureds" further our understanding by examining potential issues between the insurance sector and policyholder. Using a realistic disaster scenario of a large eruption, the chapter describes two companies' very different yet possible approaches to managing the situation. This analysis highlights the numerous insurance-related challenges to consider. Blong et al. argue that clear communication between the insurance sector and policyholder is dependent on informed understanding of the nature of volcanic hazards and terminology, insurance wordings and potential losses. The chapter also explores examples of insurance case law from the: 1991 eruption of Pinatubo in the Philippines; 1995 eruption of Ruapehu in New Zealand; 1980 eruption of Mount St. Helens in the USA; and, 2010 Eyjafjallajökull eruption in Iceland, to further highlight issues that arise in interpreting insurance contracts.

Clear communication, through the use of standardised Volcanic Alert Level (VAL) systems, is also central to the next chapter. Used as a communication tool to inform at-risk populations of the status of activity at specific volcanoes, Potter et al. in the chapter entitled "Challenges and Benefits of Standardising Early Warning Systems: A Case Study of New Zealand's Volcanic Alert Level System" explore standardising VAL systems across New Zealand and internationally. While the benefits are many, the key challenges further highlight the importance of context; that is, the uniqueness of each volcanic system, different needs and perspectives of end-users and, different response actions associated with the spatial and temporal differences in activity.

Volcanic hazard maps are a major tool for the visual communication of hazard and risk to a wide range of audiences. Maps are a coded form of communication, and the visual design and ability of the receiver to decode the message significantly impacts on how hazard maps are understood and applied. Thompson et al. in the chapter entitled "More Than Meets the Eye: Volcanic Hazard Map Design and Visual Communication" review case studies of volcanic crises and interdisciplinary research that addresses the relationship between hazard maps, visual design, and communication. They conclude that future technological innovations will create improved opportunities for people to read, process, and share visual information. However, audience needs and perspectives must continue to be understood in order that hazard maps and visual communications are accessible and meet the needs of users.

To exemplify the importance of the visual representation of hazard and risk, Webley and Watson in "The Role of Geospatial Technologies in Communicating a More Effective Hazard Assessment: Application of Remote Sensing Data" provide a detailed summary of how satellite imagery and geospatial technologies inform real-time analysis, communication and decision-making. Case studies from the 2010 eruption of Merapi, Indonesia; 2012-13 eruption of Tolbachik on the Kamchatka Peninsula; and, 2014-15 eruption of Bárðarbunga, Iceland further illustrate how remote sensing data have been applied during volcanic crises. Overall, Webley and Watson identify important aspects of sensors and technologies relevant to volcanic hazard assessment in a way that is easy to understand with limited knowledge of remote sensing methodologies.

While the science of volcanology rests within a positivist tradition, risk communication does not and is very much socially framed by the 
values and cultures of both the sender and receiver of the message. Dixon and Beech, in the chapter entitled "Re-enchanting Volcanoes: The Rise, Fall, and Rise Again of Art and Aesthetics in the Making of Volcanic Knowledges", remind us of this and take an expanded notion of communication to outline the history of how knowledge of volcanoes was produced and disseminated during the 18th and 19th centuries, thus bringing Part 3 back to reflect on past experiences and learnings.

The notion of the past informing present-day preparedness activities is explored by Kitagawa in the chapter entitled "Living with an Active Volcano: Informal and Community Learning for Preparedness in South of Japan”. Kitagawa provides a local perspective of how residents have learned to live with the everyday threat of volcanic hazards with respect to Sakurajima Volcano in Japan. Emanating from these lessons are two local lores: 'do not rely on authorities' and 'be frightened effectively', which Kitagawa argues, enhance preparedness through the development of agency and being alert but not alarmed. At the community level, collaborative partnerships have had a positive influence on enhancing community participation and collective efficacy, where decisions are made and information and ideas are exchanged. This approach has led to societal-level empowerment and trust between individuals and officials.

Dohaney et al. in the chapter entitled "Using Role-Play to Improve Students' Confidence and Perceptions of Communication in a Simulated Volcanic Crisis" argue that the theory, skills and protocols behind effective volcanic crisis communication are often not taught to young scientists. To address this gap, Dohaney et al. outline and evaluate an innovative role-play exercise where University students are able to practice crisis communication through a realistic real-time scenario. The methodology successfully increases students' confidence to communicate and knowledge of science communication.

Sharpe in the chapter entitled "Learning to Be Practical: A Guided Learning Approach to Transform Student Community Resilience When Faced with Natural Hazard Threats" also investigates the use of a classroom based learning approach to move beyond knowledge creation to promote action. The methodology used experiential learning, reflection and the act of playing out the threats from hazards allowing students aged between 11 and 14 to explore key issues of risk, response and preparedness for themselves and their family. The lessons were planned in order to fit within the National Curriculum and involved guided research and investigation through websites, videos and mapping exercises; the creation of student films; and, a homework task to produce an emergency Go-Bag with parents. A questionnaire completed by the students three weeks after the learning identified that $75 \%$ of the sample had collated their emergency kits with their parents and 55\% felt more prepared as a family. This aligns with previous research that suggests that with the right support, students can be agents of change within the family.

The final crisis communication tool to be considered is social media. Sennert et al. in "Role of Social Media and Networking in Volcanic Crises and Communication" examine the role of social media as an often preferred source for news. Focusing on two projects, led by the first and second authors of this chapter, a set of recommendations are made in an effort to assist volcano observatories and government officials in using various social media platforms to their advantage. As new technologies and platforms are developed, some of these recommendations may become obsolete. Overall, however, many of them will remain pertinent to volcanic crisis communication, well into the future. 
Open Access This chapter is distributed under the terms of the Creative Commons Attribution 4.0 International License (http://creativecommons.org/licenses/by/4.0/), which permits use, duplication, adaptation, distribution and reproduction in any medium or format, as long as you give appropriate credit to the original author(s) and the source, a link is provided to the Creative Commons license and indicate if changes were made.
The images or other third party material in this chapter are included in the chapter's Creative Commons license, unless indicated otherwise in a credit line to the material. If material is not included in the chapter's Creative Commons license and your intended use is not permitted by statutory regulation or exceeds the permitted use, you will need to obtain permission directly from the copyright holder. 